\title{
Ultrasound vs Magnetic Resonance in the Assessment of CNS Anomalies
}

\author{
Snezana Crnogorac, Aleksandar Jurišić, Aleksandar Grdinić
}

\begin{abstract}
Central nervous system (CNS) malformations are some of the most comon congenital abnormalities. Long-term follow-up studies suggest that the incidence may be as high as 1 in 100 births. Imaging technologies have been remarkably improved and contributed to prenatal evaluation of fetal CNS development and assessment of CNS abnormalities. The routine examination of the fetal brain can be achieved with axial planes by conventional transabdominal ultrasonography. In order to provide a complete view of the different brain structures a detailed fetal neurosonogram requires additional coronal and sagittal views. Three-dimensional (3D) sonography should be performed transvaginally using the multiplanar approach. Transvaginal high-resolution 3D ultrasound can demonstrate cerebral fine vascular anatomy such as medullary vessels, intracranial calcification, vascular abnormalities. Parallel slicing provides a tomographic visualization of internal morphology similar to magnetic resonance imaging (MRI). Fetal MRI appears to be a useful adjunct to ultrasound to confirm or exclude certain abnormalities. MRI is a valuable complementary tool to detailed neurosonography which allows an evaluation of the normal brain maturation from the second trimester. It also offers a higher diagnostic performance for some congenital abnormalities such as cortical development or posterior fossa assessment.
\end{abstract}

Keywords: Prenatal diagnosis, Transabdominal/transvaginally ultrasonography, Three-dimensional sonography, Magnetic resonance imaging, Congenital CNS malformations.

How to cite this article: Crnogorac $S$, J urišić $A$, Grdinić $A$. Ultrasound vs Magnetic Resonance in the Assessment of CNS Anomalies. Donald School J Ultrasound Obstet Gynecol 2013;7(4):496-499.

\section{Source of support $\mathrm{Nil}$}

Conflict of interest: None declared

\section{INTRODUCTION}

Central nervous system (CNS) malformations are some of the most common of all congenital abnormalities. Longterm follow-up studies suggest however that the incidence may be as high as 1 in 100 births. Cerebral anomalies at birth account for approximately $9 \%$ of all isolated anomalies and are present in $15.9 \%$ of babies with multiple malformations. Prenatal detection and accurate definition of CNS malformations are important because these anomalies frequently have a severe prognosis and are often associated with genetic syndromes. ${ }^{1} \mathrm{U}$ Itrasound has been used more than 30 years as the main modality to make diagnose fetal CNS anomalies. The CNS is the first system investigated in utero by ultrasound as well as anencephaly is the first congenital anomaly recognized by ultrasound before birth. Imaging technologies have been remarkably improved and contributed to prenatal evaluation of fetal CNS development and assesment of CNS abnormalities. ${ }^{2}$

\section{MATERIALS AND METHODS}

High frequency ultrasound transducers increase resolution and decrease penetration of the sound beam. The choice of the optimal transducer and operating frequency is influenced by a number of factors. Most basic examinations are satisfactorily performed with 3 to $5 \mathrm{M} \mathrm{Hz}$ transabdominal transducers. Fetal neurosonography requires transvaginal examinations that are usually performed with transducers 5 to $7 \mathrm{M} \mathrm{Hz} .{ }^{3}$ Color and power Doppler may be used mainly to identify cerebral vessels.

By conventional transabdominal ultrasonography whole CNS of fetuses can be demonstrated, but this approach has several obstacles such as maternal abdominal wall, especially in obese women, placenta, fetal cranial bones and head position. The recognition of abnormal finding during basic ultrasound scan is indication for fetal neurossonography. ${ }^{4}$

Transabdominal sonography is the technique of choice to investigate the fetal CNS during late first, second and third trimesters of gestation in low risk pregnancies. The examination should include the evaluation of the fetal head and spine. ${ }^{5}$ Two axial planes allow visualization of the cerebral structures, first one passes trough cavum septi pellucidi (CSP) and lateral ventricles and the secod one trough the posterior fossa and cerebellum, allow us to display number of fetal head structures, such as: skull, cerebral hemispheres, interhemispheric structures, lateral ventricles, arachnoidal spaces, cerebellum, cisterna magna, etc. ${ }^{6}$ Structures that are usually noted in a basic ultrasound examination (Fig. 1) of the fetal CNS are:

- Head shape

- Lateral ventricles

- CSP

- Thalami

- Cerebellum

- Cisterna magna

- Spine.

Biometry is an essential part of the sonographic examination of the fetal head with a third plane, transthalamic plane. Standard examination includes the 


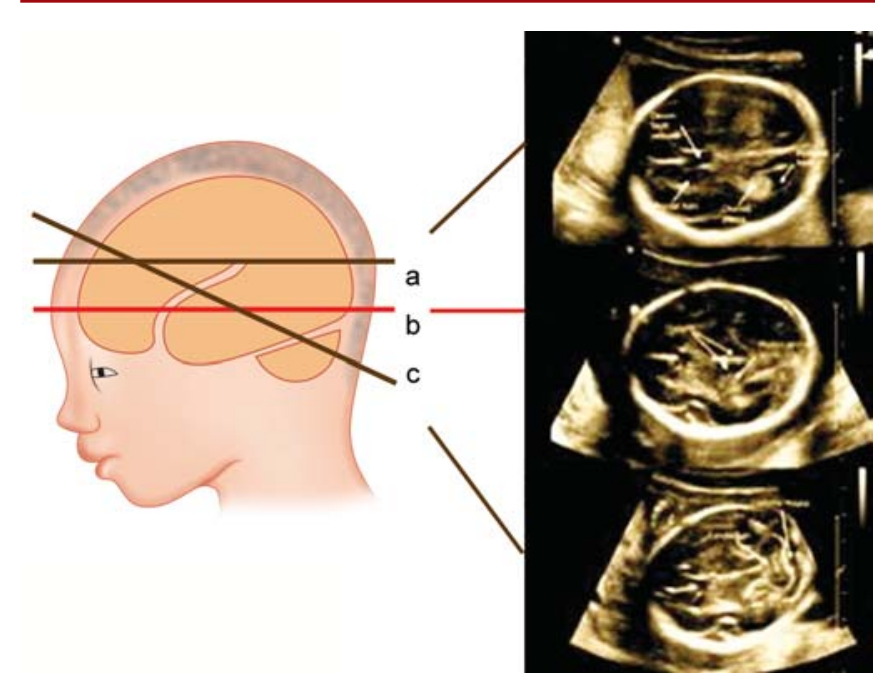

Fig. 1: Three-axial planes

measurement of the biparietal diameter, head circumference, internal diameter of atrium, transvrese cerebellar diameter and cisterna magna depth. ${ }^{7}$

The brain, how ever, is three-dimensional (3D) structure and should be assessed in basic three planes of sagittal, coronal and axial sections. 3D sonography is fundamental tool for a complete assessment of the fetal CNS. Transvaginal sonographic approach to the fetal brain provides detailed information about the fetal intracranial morphology. 8

It is possible through the anterior and posterior fontanelles and sagittal suture. This approach offers sagittal and coronal views of the brain from fetal parietal direction.
Serial oblique sections by the same window reveal the antracranial morphology in detail. ${ }^{9,10}$

Using TV 3D probes it is possible to evaluate the fetal brain starting from its early stages of development, thus allowing diagnosos of some brain anomalies in the first trimester. ${ }^{11}$ 3D ultrasound may allow detection of pathological CNS development at an earlier gestational age. Fetal brain develops rapidly in the second trimester and therefore early scanning covers only selected CNS anomalies and serious and detailed observation in the second trimester is necessary. ${ }^{12}$

This approach allows the demonstration of large number of fetal brain structures such as: corpus callosum, cerebellar vermis, the three-horn view, hippocampus and, etc.

L ast generation of 3D ultrasound has multiple functions like:

- Multiplanar imaging of the intracranial structure.

- Tomographic ultrasound imaging (TUI) of the fetal brain-allows simultaneous visualization of multiple parallel slices in one of three orthogonal planes, quite similar to pictures of magnetic resonance imaging (M RI) (Fig. 2).

- Volume contrast imaging-allows obtaining a thick slice of the fetal brain with simultaneous visualization of two orthogonal planes.

- 3D sonoangiography of the brain circulation during the whole pregnancy.

- Surface anatomy imaging the surface visualization of different structures such as the calvarium. ${ }^{13}$
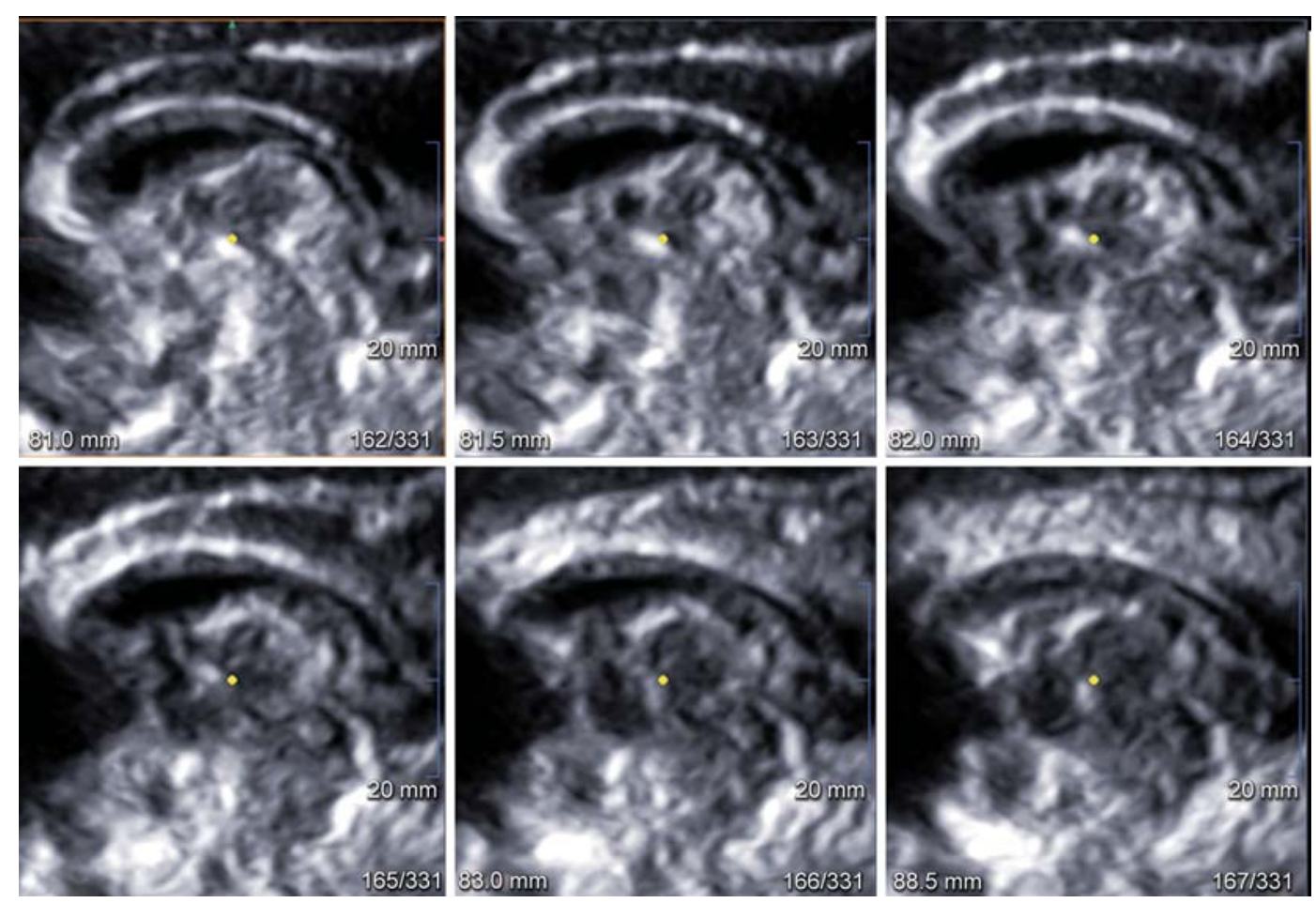

Fig. 2: Tomographic ultrasound imaging of the fetal brain-corpus callosum 
Surface mode shows not only fetal head abnormality such as acrania but also normal cranial bones and sutures in the first trimester. Rotation of the brain volume image and multiplanar analysis enable tomographic visualization as M RI. Sonoangiography shows the brain circulation threedimensionally and extracted volume images of target organ provide information on detailed intracranial conditions. The technology is easy, noninvasive and produces comprehensible and objective information. ${ }^{14}$ Bony structural imaging of the calvaria and vertebrae are useful in cases of spina bifida (Fig. 3). In multiplanar imaging of the fetal brain it is possible to demonstrate sagittal, coronal and axial section of the brain which can not be demonstrated from parietal direction by 2D US. V olume analysis of the fetal brain by 3D US, can provide objective assessment of enlarged ventricles and intracranial lesions.

This method also provides longitudinal study of maldevelopment of CNS by serial neuroscans through whole pregnancy. 3D US is particularly useful in the evaluation of midline anomalies due to reconstruction of midsagittal plane by using multiplanar or $\mathrm{VCl}$ mode. This view offers simultaneous visualization for example corpus callosum and vermis. This is helpful in recognizing the cause of ventriculomegaly (VM). If we can see normal corpus callosum and vermis, then it is probably isolated $\mathrm{VM}$ which is mainly due to aqueduct stenosis. 3D US is also useful in the evaluation of posterior fossa, particularly cerebellar vermis and fourth ventricle. ${ }^{15}$

While ultrasound remains the method of choice for screening examinations of the fetus, MRI is playing an important role in the detection and classification of malformations not diagnosable by ultrasonography alone. A dvances in fast single-shot M R sequences have allowed high-resolution, high-quality imaging of the moving fetus. Preferable sequences to be applied are a true fast imaging steady precession (true-FISP) or a half-Fourier acquired single-shot turbo spin-echo (H A STE) sequence. ${ }^{16} A$ dvances in fast M RI technology has improved image resolution and minimized artefacts due to fetal movement and maternat respiratory motion. M RI is not influenced by fetal location, head position of the fetus and ossification of cranial bones. MRI has a capital role in depicting brain maturation, especially cortical formation that follows temporospatial pattern and in detecting devel opmental abnormalities of the cortex. In multiplanar imaging MRI has superiority in assessment of whole intracranium including the brainstem, posterior fossa and gyral formation with better contrast between different tissue (Fig. 4). In cases of microcephaly, $\mathrm{MRI}$ is much more helpful than transfontanelle ultrasound exam.
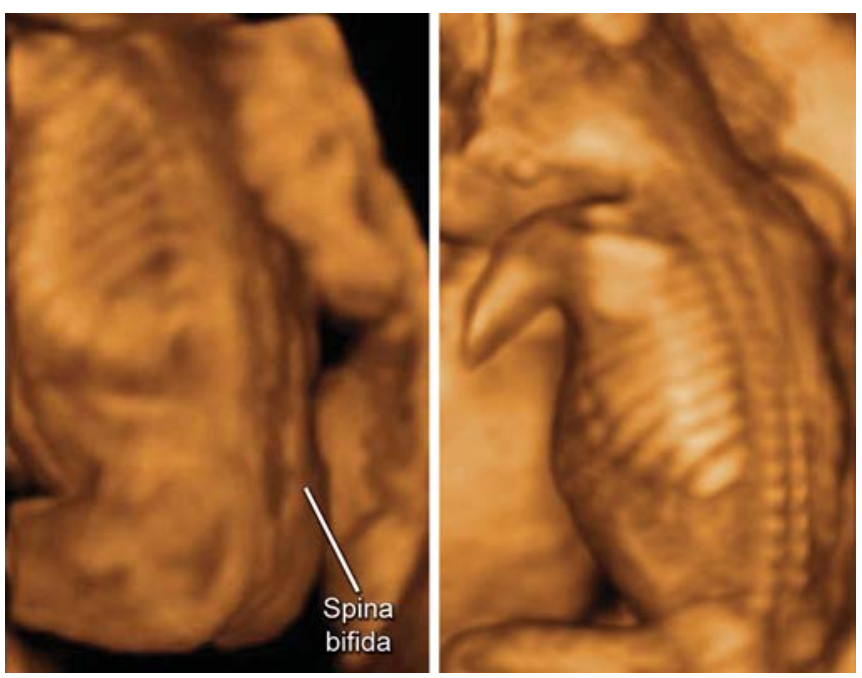

Fig. 3: Normal structure of fetal vertebrae and vertebral structure complicated by spina bifida at 28 weeks of gestation

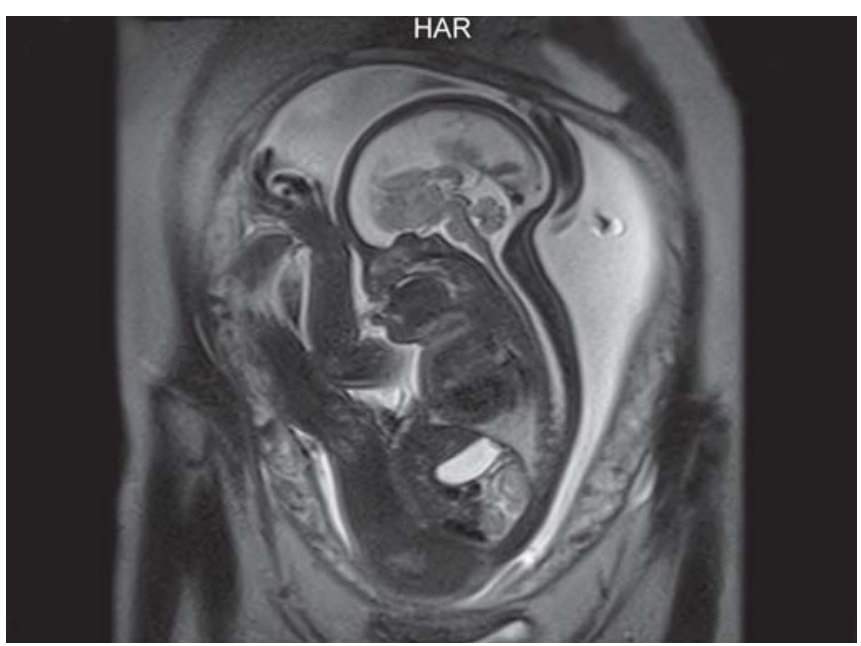

Fig. 4: MRI posterior fossa

\section{REFERENCES}

1. Timor-Tritsch IE, Peisner DB, Raju S. Sonoembryology: an organ-oriented approach using a high-frequency vaginal probe. J Clin Ultrasound 1990 M ay;18(4):286-298.

2. Benoit B, Hafner T, Kurjak A, K upesic S, B ekavac I, B ozek T. Three-dimensional sonoembryology. J Perinat Med 2002;30(1):63-73.

3. Chaoui R, Heling K S, K ainer F, K arl K. Fetal neurosonography using 3-dimensional multiplanar sonography. Z Geburtshilfe N eonatol 2012 A pr;216(2):54-62.

4. Herman-Sucharska I, B ekiesiñska-Figatowska M, U rbanik A. Fetal central nervous system malformations on $M R$ images. Brain Dev 2009 M ar;31(3):185-199.

5. M onteagudo A, Timor-Tritsch IE, M oomju M . In utero detection of ventriculomegaly during the second and third trimester by transvaginal sonography. Ultrasound Obstet Gynecol 1994 M ay;4(3):193-198.

6. Pooh RK, Nakagawa Y, Nagamachi N, Pooh KH, M aeda K, Fukui $\mathrm{R}$, A ono T. Transvaginal sonography of the fetal brain: detection of abnormal morphology and circulation. Croat $\mathrm{Med}$ J 1998 J un;39(2):147-57. 
7. Pogledic I, M eyberg-Solomayer G, Reith W. Fetal M RI and ultrasound of congenital CNS anomalies. Radiologe 2013 Feb;53(2):116-122.

8. Girard N, Chauomoitre K, Confort-Gouny S, Viola A, Levrier $O$. $M$ agnetic resonance imaging and the detection of fetal brain anomalies, injury and physiologic adaptations. Curr O pin O bstet Gynecol 2006 A pr;18(2):164-176.

9. Timor-Tritsch IE, M onteagudo A. Transvaginal fetal neurosonography: standardization of the planes and sections by anatomic landmarks. Ultrasound Obstet Gynecol 1996 Jul;8(1):42-47.

10. Pooh RK, Shiota K, K urjak A. I maging of the human embryo with magnetic resonance imaging microscopy and highresolution transvaginal three-dimensional sonography: human embryology in the 21st century. A m J Obstet Gynecol 2011 Jan;204(1):77-79.

11. Fong KW, Ghai S, Toi A, Blaser S, W insor EJ, Chitayat D. Prenatal ultrasound findings of lissencephaly associated with M iller-Dieker syndrome and comparison with pre- and postnatal magnetic resonance imaging. Ultrasound Obstet Gynecol 2004 Dec;24(7):716-723.

12. Pooh RK. Neurosonoembryology by three-dimensional ultrasound. Semin Fetal N eonatal M ed 2012 Oct; 17(5):261-268.

13. Li Y, Estroff JA, Mehta TS, Robertson RL, Robson $C D$, Poussaint TY, Feldman HA, W are J, L evine D. U Itrasound and M RI of fetuses with ventriculomegaly: can cortical development be used to predict postnatal outcome? A m J Roentgenol 2011 J un;196(6):1457-1467.
14. Pooh RK, Pooh K. Transvaginal 3D and Doppler ultrasonography of the fetal brain. Semin Perinatol 2001 Feb;25(1):38- 43.

15. M alinger $G, L$ ev $D$, Lerman-Sagie T. Is fetal magnetic resonance imaging superior to neurosonography for detection of brain anomal ies? U Itrasound O bstet Gynecol 20020 ct;20(4):317-321.

16. Ertl-Wagner B, Lienemann A, Strauss A, Reiser M F. Fetal magnetic resonance imaging: indications, technique, anatomical considerations and a review of fetal abnormalities. Eur Radiol 2002 A ug;12(8):1931-1940.

\section{ABOUT THE AUTHORS}

\section{Snezana Crnogorac}

Department of Obstetrics and Gynecology, Clinic for O bstetrics and Gynecology, Clinical Centre of M ontenegro, Podgorica, M ontenegro

Correspondence Address Str. L jubljanska bb. 81000 Podgorica M ontenegro, Phone: +38220412371, e-mail: snezanacrnogorac1@gmail.com

\section{Aleksandar Jurišić}

Department of Obstetrics and Gynecology, Clinic for O bstetrics and Gynecology 'N arodni front', B elgrade, Serbia

\section{Aleksandar Grdinić}

Department of Obstetrics and Gynecology, Clinic for O bstetrics and Gynecology, Clinical Centre of M ontenegro, Podgorica, M ontenegro 